\title{
Association between 25-Hydroxyvitamin D, Parathyroid Hormone, Vitamin D and Calcium Intake, and Bone Density in Healthy Adult Women: A Cross-Sectional Analysis from the D-SOL Study
}

\author{
Marcela M. Mendes ${ }^{1, *}$, Kathryn H. Hart ${ }^{1}\left(\mathbb{D}\right.$, Susan A. Lanham-New ${ }^{1}$ and Patrícia B. Botelho ${ }^{2,3}$ \\ 1 Department of Nutritional Sciences, University of Surrey, Guildford GU2 7XH, UK; \\ k.hart@surrey.ac.uk (K.H.H.); s.lanham-new@surrey.ac.uk (S.A.L.-N.) \\ 2 Postgraduate program of the Faculty of Nutrition, Federal University of Goiás, Goiânia 74605-080, Brazil; \\ patriciaborges.nutri@gmail.com \\ 3 Faculty of Health Sciences, University of Brasília, Brasília 70910-900, Brazil \\ * Correspondence: m.moraesmendes@surrey.ac.uk; Tel.: +44-(0)-1483-689222
}

Received: 1 May 2019; Accepted: 29 May 2019; Published: 4 June 2019

\begin{abstract}
There is still limited data on the association between 25-hydroxyvitamin D (25(OH)D), parathyroid hormone (PTH), and bone health in healthy younger adults, particularly in Latin America. This cross-sectional analysis aimed to investigate the associations of $25(\mathrm{OH}) \mathrm{D}$ and plasma PTH concentrations with bone parameters, and potential confounders, in women living in a high (England) or low (Brazil) latitude country. Bone was assessed by either peripheral quantitative computed tomography (pQCT) (England) or dual-energy x-ray absorptiometry (DXA) scan (Brazil), serum 25(OH)D concentrations by high performance liquid chromatography tandem mass spectrometry (HPLC-MS) and PTH by the chemiluminescent method. In participants living in England, total volumetric bone mineral density (vBMD) was significantly higher in women $<29$ years compared to $\geq 30$ years, and total and cortical vBMD values at the $66 \%$ site were negatively correlated with weight and body mass index (BMI). In participants living in Brazil, age was positively correlated with bone mineral density (BMD) at the femur and bone mineral content (BMC), and weight, BMI, and body fat were correlated with BMD (lumbar spine and femur) and BMC. PTH concentrations were negatively correlated with $25(\mathrm{OH}) \mathrm{D}$ concentrations, and the prevalence of secondary hyperparathyroidism was $28.6 \%(n=14)$ in participants with concentrations $<25 \mathrm{nmol} / \mathrm{L}$ and $12.2 \%(n=41)$ with concentrations between 25 and $49.9 \mathrm{nmol} / \mathrm{L}$, compared to $6.3 \%(n=79)$ in those with concentrations $\geq 50 \mathrm{nmol} / \mathrm{L}$. In conclusion, weight and BMI were significantly correlated with bone parameters in both groups and age was significantly correlated with BMD at the femoral neck for women living in Brazil only. Although $25(\mathrm{OH}) \mathrm{D}$ concentrations were not correlated to bone parameters at any sites, in either country, PTH concentrations showed a significant correlation with total vBMD at the $66 \%$ site for women living in England. Secondary hyperparathyroidism was more common amongst those with deficient and insufficient vitamin D status.
\end{abstract}

Keywords: 25-hydroxyvitamin D; parathyroid hormone; bone; vitamin D; Brazil; bone mineral density

\section{Introduction}

Calcium and vitamin D are essential nutrients with a major role in bone health. Calcium is the most abundant mineral in the body and is essential to functions related to vascular contraction, muscle function, nerve transmission, intracellular signaling, and hormonal secretion [1,2]. Bone acts as the calcium reservoir to maintain constant calcium homeostasis, with around $99 \%$ of the organism's 
calcium supply stored in the bones and teeth. Vitamin D also plays a key role in calcium homeostasis, promoting calcium absorption in the gut and resorption in the kidney, as well as stimulating bone formation and remodeling [3]. Therefore, optimal intakes of calcium and vitamin D are generally regarded as fundamental factors in the prevention and treatment of osteoporosis.

The associations of calcium intake, vitamin D intake, and vitamin D status with bone mineral density (BMD) and the risk of fractures have been studied extensively over the past decades, but mostly in the elderly population [4-6]. An extensive amount of human evidence supports the contribution of calcium for bone homeostatic regulation and treatment of osteoporosis. Observational studies as well as randomized controlled trials have generally shown that higher calcium and vitamin D intakes (either from food or supplementation), compared to lower intakes, may have significant benefits to bone health and reduce the risk of osteoporosis [1,7-9].

Parathyroid hormone (PTH), a hormone secreted by the parathyroid glands in response to low serum calcium levels, is also well recognized as a fundamental part of bone homeostasis. PTH triggers the hydroxylation of 25-hydroxyvitamin $\mathrm{D}(25(\mathrm{OH}) \mathrm{D})$ to the active form, 1,25-dihydroxyvitamin $\mathrm{D}\left(1,25(\mathrm{OH})_{2} \mathrm{D}\right)$, leading to enhanced intestinal absorption of calcium. Chronic elevated PTH concentrations can have significant negative impacts on BMD and consequently increase the risk of fractures over time $[2,3,9]$. Low dietary calcium and vitamin D intakes, as well as an inadequate vitamin D status, can be independent contributors to high PTH concentrations $[10,11]$. The negative correlation between PTH and vitamin D, and negative effects of higher PTH on bone health, have been previously demonstrated, but mostly in elderly and/or osteoporotic populations [11-15], and therefore there is still limited data on healthy adults, particularly in Latin America and Brazil [16].

This analysis aimed to investigate the associations of serum $25(\mathrm{OH}) \mathrm{D}$ and plasma PTH concentrations, as well as habitual dietary vitamin $\mathrm{D}$ and calcium intakes, age, and adiposity with bone health parameters assessed by either peripheral quantitative computed tomography (pQCT) or dual-energy x-ray absorptiometry (DXA) in in two groups of adult Brazilian women living in opposite latitudes.

\section{Materials and Methods}

A cross-sectional analysis of endocrine status (specifically 25(OH)D and PTH concentrations), calcium and vitamin D intake, age and adiposity, and bone mineral density was conducted in 130 healthy adult Brazilian women living in England $\left(51^{\circ} \mathrm{N}\right)$ and healthy adult Brazilian women living in Brazil $\left(16^{\circ} \mathrm{S}\right)$, recruited for the D-SOL study (Interaction between Vitamin D Supplementation and Sunlight Exposure in Women Living in Opposite Latitudes-clinicaltrials.gov as NCT03318029). The D-SOL study recruited adult women aged 20 to 59 years with Brazilian nationality (born in Brazil and having at least one parent born in Brazil).

\subsection{Exclusion Criteria}

The participants were screened according to exclusion criteria that included potential cofounders likely to affect vitamin D metabolism (osteoporosis therapy, anti-estrogen treatment, antiepileptic drugs, cancer treatment), taking containing vitamin $\mathrm{D}$ (if the prospective participants agreed to stop vitamin D supplementation to join the study, a wash-out period of 8 weeks prior to commencing the trial was accepted), being pregnant or planning a pregnancy during the study period, menopause status (defined as the permanent cessation of menstruation), and living in the UK for less than 3 months at the commencement of the study (for England participants only). All participants provided written informed consent at the commencement of the study.

\subsection{Data Collection}

The dietary intake of participants, particularly vitamin D and calcium, was determined by 4 consecutive days of estimated diet diaries, including one weekend day. Participants were instructed 
by the research team on how to correctly complete the diary and asked to give as much detail as possible of every meal, including portion size.

Dietary intake data obtained from participants in the England cohort were analyzed using the Nutritics ${ }^{\circledR}$ nutritional analysis software (version 4.0, Dublin, Ireland), (UK Composition of Foods Integrated Dataset (CoFID) including McCance and Widdowson 7th edition (70)) and those collected in Brazil were analyzed via the Dietwin ${ }^{\circledR}$ software (Version 13 (3090), Rio Grande do Sul, Brazil) (Brazilian Food Composition Table (TACO) (113) and the food composition database from the Brazilian Institute of Geography and Statistics (IBGE), as well as the United States Department of Agriculture (USDA) food composition database).

Participants were instructed to wear light clothing on the day of the visits to minimize different additional weights from clothing. For weight measurement, participants were asked to remove shoes, socks, and heavy coats before stepping on the scale. For the England trial, weight to the nearest $0.1 \mathrm{~kg}$ and body fat was obtained using a Tanita Body Composition Analyser MC-180MA (Tanita Cooperatives, Tokyo, Japan). For the Brazil trial, weight was measured to the nearest $0.1 \mathrm{~kg}$ using a standard weighing scale (Balmak ${ }^{\circledR}$, Santa Bárbara d'Oeste, SP, Brazil) and body composition was determined via DXA scan (GE Healthcare LunarTM DPX NT + 152000, GE Medical Systems, Madison, WI, USA). Anthropometric methods were standardized between the different researchers involved in the study performing the measurements in each country to minimize inter-evaluator variations. Standing height was measured using a wall stadiometer to the nearest $0.1 \mathrm{~cm}$, with participants in an upright posture and barefoot with heels close together and as close as possible to the wall. Waist circumference was measured with a non-extendable standard measure tape, at the narrowest point of the torso, to the nearest $0.1 \mathrm{~cm}$. If this point could not be estimated, the level of the belly button was used as a reference point [17].

An overnight fasted $(8 \mathrm{~h})$ blood sample was collected by venipuncture by trained phlebotomists. Processed serum and plasma samples were divided into aliquots and stored at $-80^{\circ} \mathrm{C}$ at the University of Surrey, prior to analysis. Samples collected in Brazil followed the exact same procedures and were temporarily stored at $-80^{\circ} \mathrm{C}$ at the Federal University of Goiás, and sent to be stored at the University of Surrey as well, prior to analysis.

\subsection{Laboratory Analysis}

Serum 25(OH)D concentrations were determined by the HPLC-MS/MS method on a Waters Acuity UPLC (Triple Quadrupole) TQD ${ }^{\circledR}$ System using a Pentafluorophenyl (PFP) column following supported liquid extraction (SLE). Laboratory intra- and inter-assay coefficients of variation (CV) were $5.6 \%$ and 7.8\%, respectively. Calcium, albumin, and PTH concentrations were measured using Abbott Architect kits. Serum calcium was measured by using an endpoint spectrophotometric reaction based on the o-cresolphthalein complexone methodology, and serum albumin was measured by using an endpoint spectrophotometric reaction based on the bromocresol green solution dye binding methodology. Serum calcium concentrations were adjusted for albumin concentrations. Plasma intact PTH was measured by in vitro chemiluminescent microparticle immunoassay (CMIA). The manufacturer's quoted inter-assay $\mathrm{CV}$ for calcium was $<3 \%$, for albumin $<3.8 \%$, and for PTH $4 \%$.

\subsection{Bone Measurements}

For the England trial, a peripheral quantitative computed tomography scan (pQCT; XCT 2000, Stratec Medizintechnik GmbH, Pforzheim, Germany) was performed on the participant's non-dominant forearm to measure volumetric bone mineral density at the $4 \%$ and $66 \%$ radial site. pQCT was performed by the same experienced operator to scan all participants' radii. For total density and trabecular density, these were calculated using previously published reference data for white Caucasian European women [18] using the equation: Z-score $=(($ individual value - expected value for age $) /$ reference standard deviation (SD)). For participants in Brazil, whole body bone mineral density, lower spine (L1-L4) density, and left femur bone mineral density were measured via DXA scan (dual-energy X-ray absorptiometry). The same experienced operator performed all DXA scans with all participants. 
Z-scores of Brazilian participants for the lumbar spine (L1-L4) and femur (femoral neck) were automatically calculated by the DXA scan, which used white Caucasian Women as a reference [19].

The same cut-off values for Z-score classification (i.e., Z-score $\geq-2.0$ defined as normal (low-risk score) and Z-score $\leq-2.0$ defined as low bone mineral for age) were applied to pQCT and DXA scans.

The study received a favorable ethical opinion from the University of Surrey (UEC/2016/009/FHMS) and Federal University of Goiás Ethics Committees and from the Brazilian National Ethics Committee (CONEP) (CAAE 62149516.9.0000.5083, CEP-UFG n²013222; CONPEP n ${ }^{\circ}$ 1972029; respectively).

\subsection{Statistical Analysis}

Statistical analysis of the data was done using SPSS software for Windows (version 25.0; IBM Corp, Armonk, NY, USA). Data were tested for normal distribution using the Kolmogorov-Smirnov tests. Non-normally distributed variables were log transformed and reported on the original scale. Non-parametric tests were used when log transforming did not normalize the data. Descriptive statistics were determined for all variables. Continuous variables are presented as mean \pm standard deviation (SD) for normally distributed variables or as median $(25 \%, 75 \%$ percentiles) for not normally distributed. For categorical variables, the frequency and percentage are reported.

Baseline characteristics (age, weight, BMI, waist circumference, dietary intakes, and biomarkers) were compared between countries, by independent t-tests, or Mann-Whitney U tests if appropriate.

For each country separately, ANOVA, or the corresponding non-parametric Kruskal-Wallis test, were used to compare bone parameter measurements between age tertiles and between vitamin D status groups. Pearson's correlation, or the corresponding non-parametric Spearman rho, were applied to investigate the correlation between bone parameter measurements and $25(\mathrm{OH}) \mathrm{D}$ or PTH concentrations as well as vitamin $\mathrm{D}$ and calcium intakes.

Regression models were used to investigate the association between bone parameters and age and anthropometric measurements.

Results are presented separately for each country as measurements derived from different methodologies. A $p$ value of $<0.05$ was considered significant.

\section{Results}

\subsection{Participant Characteristics}

Baseline anthropometric, dietary, and biochemical characteristics are presented in Table 1, by country of residence. Brazilian women living in England were significantly older $(p<0.001)$, heavier $(p=0.002)$, and had a greater waist circumference $(p<0.001)$ than those living in Brazil. Amongst the 130 participants, $63 \%$ identified themselves as white and $33.3 \%$ as brown (mixed). The proportion of white women in the England cohort was higher (78.6\% white compared to $1.8 \%$ black and $17.9 \%$ brown) while in the Brazil cohort there was an even distribution between white and brown $(51.9 \%$ and $44.3 \%$, respectively), with only $2.5 \%$ black.

Overall (women living in Brazil combined with those living in England, $n=114$ ), mean habitual vitamin D dietary intake was $2.44 \pm 1.91 \mu \mathrm{g} /$ day and mean calcium intake was $627.053 \pm 315.45 \mathrm{mg} /$ day. Mean vitamin $\mathrm{D}$ and calcium intakes were significantly higher in England residents compared to Brazil residents $(p<0.001$ and $p=0.003$, respectively) (Table 1$)$. In total $(n=114), 99.2 \%$ had vitamin D intakes below the recommended $10 \mu \mathrm{g} / \mathrm{day}$ [20], with only one participant recording intakes above this threshold. Only one participant living in Brazil was on vitamin D supplementation at the time of the first screening interview and suspended the supplementation two months prior to commencing the study in order to be enrolled. For calcium, $91.2 \%$ had average intakes below the Recommended Dietary Allowance (RDA) (US) [21] of $1000 \mathrm{mg} /$ day for women $\leq 50$ years, and $77.2 \%$ below the Reference Nutrient Intake (RNI) (UK) [22] of $700 \mathrm{mg} /$ day for women $>19$ years.

In participants living in England, the mean 25(OH)D concentration was significantly lower and the PTH concentration was significantly higher than for participants in Brazil (Table 1). There 
were no significant differences between women living in England and in Brazil for serum calcium concentrations, which were within the normal range for all participants (Table 1).

Table 1. Characteristics of adult Brazilian women by country of residence $(n=130)^{1}$.

\begin{tabular}{|c|c|c|c|}
\hline & England $(n=51)$ & Brazil $(n=79)$ & $p$ Value $^{2}$ \\
\hline Age (years) & $33(28,38)$ & $27(24,31)$ & $<0.001$ \\
\hline Height (m) & $1.64 \pm 0.05$ & $1.62 \pm 0.59$ & 0.094 \\
\hline Weight (kg) & $70.11 \pm 14.22$ & $63.21 \pm 13.07$ & 0.002 \\
\hline Waist Circumference $(\mathrm{cm})$ & $86.3(77.0,96.0)$ & $70.4(66.1,77.2)$ & $<0.001$ \\
\hline $\mathrm{BMI}\left(\mathrm{kg} / \mathrm{m}^{2}\right)$ & $25.94 \pm 5.30$ & $24.01 \pm 4.88$ & 0.009 \\
\hline Body fat $(\%) \neq$ & $30.95 \pm 6.00$ & $38.65 \pm 8.52$ & $<0.001^{\mathrm{a}}$ \\
\hline Vitamin D intake ( $\mu \mathrm{g} /$ day) & $2.59(1.55,3.92)$ & $1.57(0.73,2.79)$ & $<0.001$ \\
\hline Calcium intake (mg/day) & $711.76(537.22,879.51)$ & $479.97(347.42,704.92)$ & 0.003 \\
\hline Serum $25(\mathrm{OH}) \mathrm{D}(\mathrm{nmol} / \mathrm{L})$ & $35.22 \pm 14.89$ & $75.00 \pm 22.13$ & $<0.001^{\mathrm{a}}$ \\
\hline Plasma PTH (pmol/L) & $5.39 \pm 2.07$ & $4.49 \pm 1.47$ & $0.004^{\mathrm{a}}$ \\
\hline Serum Calcium $(\mathrm{mmol} / \mathrm{L})^{3}$ & $2.30 \pm 0.07$ & $2.28 \pm 0.06$ & $0.066^{\mathrm{a}}$ \\
\hline
\end{tabular}

${ }^{1}$ Values are median (25th, 75 th percentile) or mean \pm SD. ${ }^{2}$ Statistical analysis: Mann-Whitney U unless otherwise stated; a Independent $t$-test. ${ }^{3}$ Albumin corrected serum calcium concentrations. ${ }^{*}$ Measurements derived from different methodologies (England: bio-impedance; Brazil: DXA scan).

\subsection{Bone Density}

Radial bone parameter measurements, determined by pQCT, for women living in England are shown in Table 2, stratified by the age tertiles. Total volumetric BMD at both distal and diaphyseal sites was significantly higher in women younger than 29 years of age compared to those 30 years or older $(p<0.001)$. There were no significant differences between age tertile groups in any other bone parameters. Only one participant in the England cohort (30-36 years old group) had a low Z-score (low bone mineral for age) for total volumetric BMD at the distal site. There were no significant differences between age tertile groups in weight, height, serum $25(\mathrm{OH}) \mathrm{D}$, plasma PTH, nor serum calcium.

Table 2. Radial bone densitometry assessed by peripheral Quantitative Computed Tomography (pQCT) of Brazilian women living in England by age tertiles $(n=51)^{1}$.

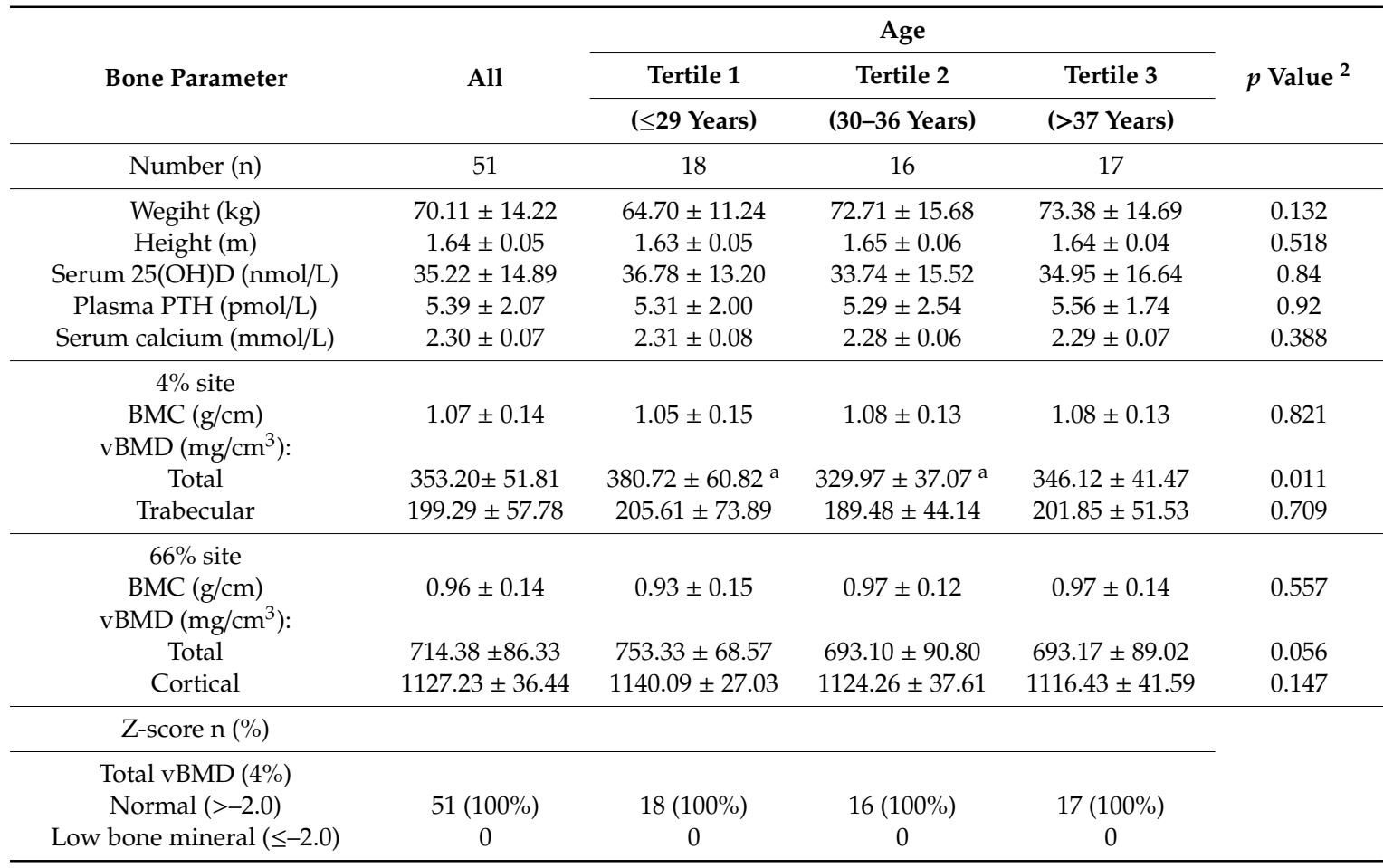


Table 2. Cont.

\begin{tabular}{|c|c|c|c|c|c|}
\hline \multirow{3}{*}{ Bone Parameter } & \multirow{3}{*}{ All } & \multicolumn{3}{|c|}{ Age } & \multirow{3}{*}{$p$ Value ${ }^{2}$} \\
\hline & & Tertile 1 & Tertile 2 & Tertile 3 & \\
\hline & & $(\leq 29$ Years $)$ & (30-36 Years) & (>37 Years) & \\
\hline \multicolumn{6}{|l|}{ Trabecular vBMD (4\%) } \\
\hline Normal $(>-2.0)$ & $51(100 \%)$ & $18(100 \%)$ & $16(100 \%)$ & $17(100 \%)$ & \\
\hline Low bone mineral $(\leq-2.0)$ & 0 & 0 & 0 & 0 & \\
\hline \multicolumn{6}{|l|}{ Total vBMD (66\%) } \\
\hline Normal $(>-2.0)$ & $48(94.2 \%)$ & $18(100 \%)$ & $13(94.8 \%)$ & $17(100 \%)$ & \\
\hline Low bone mineral $(\leq-2.0)$ & $3(5.8 \%)$ & 0 & $3(18.7 \%)$ & 0 & \\
\hline \multicolumn{6}{|l|}{ Cortical vBMD (66\%) } \\
\hline $\operatorname{Normal}(>-1.0)$ & $51(100 \%)$ & $18(100 \%)$ & $16(100 \%)$ & $17(100 \%)$ & \\
\hline Low bone mineral $(\leq-2.0)$ & 0 & 0 & 0 & 0 & \\
\hline
\end{tabular}

The characteristics of adult Brazilian women living in England divided by the tertiles of BMD can be found in the supplementary material (Tables S1-S4). Women in the lower tertile for trabecular vBMD at the $4 \%$ site were significantly taller than those in the middle tertile $(p=0.007)$. There were no significant differences in any other characteristics between BMD tertiles.

Lumbar spine (L1-L4) and femur measurements, determined by DXA, for women living in Brazil are shown in Table 3, stratified by age tertiles. The plasma PTH concentration was significantly lower in women younger than 25 years of age compared to those 31 years or older $(p=0.034)$. However, there were no significant differences between age groups in any of the bone parameters. Only two participants presented with low bone mineral values for age (Z-score $\leq-2.0)$ in the lumbar spine and both were younger than 25 years old.

Table 3. Lumbar spine and femur bone densitometry assessed by Dual-energy X-ray absorptiometry (DXA) of Brazilian women living in Brazil by age tertiles $(n=79)^{1}$.

\begin{tabular}{|c|c|c|c|c|c|}
\hline \multirow[b]{2}{*}{ Bone Parameter } & \multirow[b]{2}{*}{ All } & \multicolumn{3}{|c|}{ Age (Years) } & \multirow[b]{2}{*}{$p$ Value $^{2}$} \\
\hline & & $\begin{array}{c}\text { Tertile } 1 \\
\leq 25\end{array}$ & $\begin{array}{c}\text { Tertile } 2 \\
26-30\end{array}$ & $\begin{array}{c}\text { Tertile } 3 \\
\geq 31\end{array}$ & \\
\hline Number (n) & 79 & 33 & 25 & 21 & \\
\hline Weight (kg) & $63.21 \pm 13.07$ & $60.41 \pm 12.58$ & $64.30 \pm 12.46$ & $66.32 \pm 14.20$ & 0.239 \\
\hline Height (m) & $1.62 \pm 0.59$ & $1.61 \pm 0.05$ & $1.64 \pm 0.06$ & $1.60 \pm 0.06$ & 0.157 \\
\hline Serum $25(\mathrm{OH}) \mathrm{D}(\mathrm{nmol} / \mathrm{L})$ & $75.00 \pm 22.13$ & $78.87 \pm 27.23$ & $74.68 \pm 18.39$ & $77.15 \pm 17.61$ & 0.868 \\
\hline Plasma PTH (pmol/L) & $4.49 \pm 1.47$ & $3.96 \pm 1.25^{\mathrm{a}}$ & $4.79 \pm 1.61$ & $4.99 \pm 1.42^{\mathrm{a}}$ & 0.021 \\
\hline Serum calcium (mmol/L) & $2.28 \pm 0.06$ & $2.29 \pm 0.07$ & $2.29 \pm 0.05$ & $2.25 \pm 0.07$ & 0.26 \\
\hline \multicolumn{6}{|l|}{ Lumbar Spine } \\
\hline Number (n) & 79 & 33 & 25 & 21 & 0.537 \\
\hline $\operatorname{BMD}\left(\mathrm{g} / \mathrm{cm}^{2}\right)$ & $1.13 \pm 0.11$ & $1.12 \pm 0.12$ & $1.13 \pm 0.11$ & $1.15 \pm 0.11$ & \\
\hline \multicolumn{6}{|l|}{ Femur } \\
\hline Number (n) & 64 & 27 & 20 & 17 & 0.495 \\
\hline $\operatorname{BMD}\left(\mathrm{g} / \mathrm{cm}^{2}\right)$ & $0.98 \pm 0.10$ & $0.97 \pm 0.10$ & $0.97 \pm 0.12$ & $1.01 \pm 0.11$ & \\
\hline \multicolumn{6}{|l|}{ Total BMC } \\
\hline Number (n) & 79 & 33 & 25 & 21 & 0.204 \\
\hline $\mathrm{BMC}(\mathrm{g})$ & $2304.87 \pm 401.76$ & $2304.87 \pm 401.76$ & $2459.92 \pm 377.29$ & $2460.95 \pm 338.42$ & \\
\hline \multicolumn{6}{|l|}{ Z-score n (\%) } \\
\hline \multicolumn{6}{|l|}{ Lumbar Spine BMD } \\
\hline Normal $(>-2.0)$ & $79(97.5 \%)$ & $31(94 \%)$ & $25(100 \%)$ & $21(100 \%)$ & \\
\hline Low bone mineral $(\leq-2.0)$ & $2(2.5 \%)$ & $2(6 \%)$ & 0 & 0 & \\
\hline \multicolumn{6}{|l|}{ Z-score n (\%) } \\
\hline \multicolumn{6}{|l|}{ Femur BMD } \\
\hline Normal $(>-2.0)$ & $64(100 \%)$ & $27(100 \%)$ & $20(100 \%)$ & $17(100 \%)$ & \\
\hline Low bone mineral $(\leq-2.0)$ & 0 & 0 & 0 & 0 & \\
\hline
\end{tabular}

\footnotetext{
${ }^{1}$ Values: mean \pm SD or $\mathrm{n}(\%) ;{ }^{2}$ Statistical analysis: one-way ANOVA with post-hoc Tukey's test: values in the same row with the same superscript letters are significantly different $\left({ }^{\mathrm{a}} p=0.034\right)$.
} 
The characteristics of adult Brazilian women living in Brazil divided by the tertiles of BMD can be found in the supplementary material (Tables S5 and S6). Women in the lower tertile for lumbar spine BMD had significantly lower weight than those in the highest tertile $(p=0.034)$. Women in the highest tertile for femur BMD had significantly higher weight and BMI values than those in the lowest and middle tertiles ( $p<0.001$ for both measures). There were no significant differences in any other characteristics between BMD tertiles.

\subsection{Correlations between Bone Parameters and Age, Weight, and BMI}

Among women living in England, the BMC at the distal site (4\%) was positively correlated with weight and BMI ( $p=0.021$ and $p=0.024$, respectively). Total vBMD at the diaphyseal site $(66 \%)$ and cortical vBMD were negatively correlated with weight $(p=0.016$ and $p=0.025$, respectively) and BMI ( $p=0.018$ and $p=0.027$, respectively) (Table 4). Body fat was not correlated with any of the bone parameters. When weight and BMI were entered into a regression model as predictors of BMC at the distal site, the model did not achieve statistical significance to explain the variation $(p=0.068)$. When weight and BMI were entered into a regression model as predictors of total vBMD at the diaphyseal site, $33.7 \%(p=0.055)$ of the total variation was explained by the model, but none of the predictors had a significantly unique contribution. When weight and BMI were entered into a regression model as predictors of cortical vBMD, the model did not achieve statistical significance to explain the variation $(p=0.08)$.

Table 4. Correlations between age and adiposity and radial bone densitometry assessed by pQCT of Brazilian women living in England by age tertiles $(n=51)^{1}$.

\begin{tabular}{|c|c|c|c|c|c|c|c|c|}
\hline \multirow{2}{*}{ Bone Parameter } & \multicolumn{2}{|c|}{ Age (years) } & \multicolumn{2}{|c|}{ Weight (kg) } & \multicolumn{2}{|c|}{ BMI $\left(\mathrm{kg} / \mathrm{m}^{2}\right)$} & \multicolumn{2}{|c|}{ Body Fat (\%) } \\
\hline & r Value & $p$ Value & r Value & $p$ Value & r Value & $p$ Value & r Value & $p$ Value \\
\hline \multicolumn{9}{|l|}{$4 \%$ site } \\
\hline $\mathrm{BMC}(\mathrm{g} / \mathrm{cm})$ & 0.186 & 0.191 & 0.323 & 0.021 & 0.317 & 0.024 & 0.118 & 0.386 \\
\hline \multicolumn{9}{|l|}{$\operatorname{vBMD}\left(\mathrm{mg} / \mathrm{cm}^{3}\right)$ : } \\
\hline Total & -0.143 & 0.316 & -0.005 & 0.97 & -0.028 & 0.847 & 0.034 & 0.814 \\
\hline Trabecular & -0.007 & 0.962 & -0.118 & 0.41 & -0.112 & 0.435 & 0.085 & 0.551 \\
\hline \multicolumn{9}{|l|}{$66 \%$ site } \\
\hline BMC $(\mathrm{g} / \mathrm{cm})$ & 0.216 & 0.128 & 0.256 & 0.07 & 0.253 & 0.074 & -0.063 & 0.345 \\
\hline \multicolumn{9}{|l|}{$\operatorname{vBMD}\left(\mathrm{mg} / \mathrm{cm}^{3}\right):$} \\
\hline Total & -0.213 & 0.134 & -0.335 & 0.016 & -0.330 & 0.018 & -0.159 & 0.266 \\
\hline Cortical & -0.223 & 0.116 & -0.313 & 0.025 & -0.309 & 0.027 & -0.122 & 0.393 \\
\hline
\end{tabular}

In women living in Brazil, age was positively correlated with BMD at the femur and with BMC ( $p=0.029$ and $p=0.017$, respectively), but not BMD at the lumbar spine $(p=0.292)$. Weight, BMI, and body fat were correlated with BMD at the lumbar spine and femur and with BMC (all $p<0.01)$. (Table 5). When age together with either weight, BMI, or body fat were entered into a regression model as predictors of BMD at the femur, the model explained $64.3 \%(p<0.001)$ of the total variation, and only BMI had a significantly unique contribution $(p=0.027)$. When age together with weight, BMI, or body fat were entered into a regression model as predictors of BMC, the model explained $67 \%(p<0.001)$ of the total variation, and only weight and BMI had significantly unique contributions to the model $(p<0.001$ and $p=0.004$, respectively). When weight, BMI, and body fat were entered into a regression model as predictors of BMD at the lumbar spine, 34.2\% $(p=0.025)$ of the total variation was explained by the model, but none of the predictors had a significantly unique contribution. 
Table 5. Correlations between age and adiposity and lumbar spine and femur bone densitometry assessed by DXA of Brazilian women living in Brazil by age tertiles $(n=79)^{1}$.

\begin{tabular}{lcccccccc}
\hline \multirow{2}{*}{ Bone Parameter } & \multicolumn{2}{c}{ Age (Years) } & \multicolumn{2}{c}{ Weight $(\mathbf{k g})$} & \multicolumn{2}{c}{ BMI $\left(\mathbf{k g} / \mathrm{m}^{\mathbf{2}}\right)$} & \multicolumn{2}{c}{ Body Fat $(\%)$} \\
\cline { 2 - 9 } & r Value & $\boldsymbol{p}$ Value & r Value & $\boldsymbol{p}$ Value & r Value & $\boldsymbol{p}$ Value & r Value & $\boldsymbol{p}$ Value \\
\hline Lumbar Spine BMD $\left(\mathrm{mg} / \mathrm{cm}^{2}\right)$ & 0.120 & 0.292 & 0.337 & 0.002 & 0.298 & 0.008 & 0.252 & 0.025 \\
Femur BMD $\left(\mathrm{mg} / \mathrm{cm}^{2}\right)$ & 0.273 & 0.029 & 0.583 & $<0.001$ & 0.612 & $<0.001$ & 0.378 & 0.002 \\
Total BMC $(\mathrm{g})$ & 0.267 & 0.017 & 0.606 & $<0.001$ & 0.585 & $<0.001$ & 0.412 & $<0.001$ \\
\hline
\end{tabular}

\subsection{Correlations between Bone Parameters and Habitual Dietary Vitamin D and Calcium Intakes}

There were no significant correlations between radial bone parameter measurements, determined by $\mathrm{pQCT}$, and habitual dietary vitamin $\mathrm{D}$ and calcium intakes for women living in England. Similarly, there were no significant correlations between lumbar spine (L1-L4) and femur bone parameter measurements, determined by DXA, and habitual dietary vitamin D and calcium intakes for women living in Brazil.

\subsection{Correlations between Bone Parameters and 25(OH)D Concentrations}

There was a trend for a weak positive relationship between total volumetric BMD at the diaphyseal site and 25(OH)D concentrations for women living in England, but significance was lost after controlling for age and BMI $(p=0.171)$. There were no significant correlations between any other bone parameter measurements. There were no significant correlations between lumbar spine (L1-L4) and femur bone parameter measurements, determined by DXA, and 25(OH)D concentrations for women living in Brazil.

When stratified by vitamin D status, women with vitamin D concentrations $<25 \mathrm{nmol} / \mathrm{L}$ had significantly lower total $(p=0.0019)$ and cortical $(p=0.039) \mathrm{vBMD}$ at the $66 \%$ site than women with concentrations between 25 and $49.9 \mathrm{nmol} / \mathrm{L}$, and significantly lower total vBMD at the $66 \%$ site than women with concentrations above $50 \mathrm{nmol} / \mathrm{L}$ (0.044) (Table 6). After controlling for age and BMI, the significant differences remained only for total vBMD at the diaphyseal site, but not for cortical $\operatorname{vBMD}($ ANCOVA $p=0.047$ and $p=0.170$, respectively).

Table 6. Radial bone densitometry assessed by pQCT of Brazilian women living in England by vitamin D status $(n=51)^{1}$.

\begin{tabular}{|c|c|c|c|c|c|}
\hline \multirow{2}{*}{ Bone Parameter } & \multirow{2}{*}{ All } & \multicolumn{3}{|c|}{$25(\mathrm{OH}) \mathrm{D}$ in $\mathrm{nmol} / \mathrm{L}$} & \multirow{2}{*}{$p$ Value $^{2}$} \\
\hline & & $<25$ & $25-49.99$ & $50-74.99$ & \\
\hline Number (n) & 51 & 14 & 28 & 9 & \\
\hline Weight (kg) & $70.11 \pm 14.22$ & $76.01 \pm 17.72$ & $66.44 \pm 12.6$ & $72.33 \pm 10.20$ & 0.104 \\
\hline Height (m) & $1.64 \pm 0.05$ & $1.63 \pm 0.04$ & $1.64 \pm 0.05$ & $1.67 \pm 0.05$ & 0.340 \\
\hline BMI $\left(\mathrm{kg} / \mathrm{m}^{2}\right)$ & $25.94 \pm 5.30$ & $28.28 \pm 6.13$ & $24.73 \pm 4.84$ & $26.09 \pm 4.54$ & 0.123 \\
\hline Serum $25(\mathrm{OH}) \mathrm{D}(\mathrm{nmol} / \mathrm{L})$ & $35.22 \pm 14.89$ & $20.45 \pm 5.33$ & $34.29 \pm 5.69$ & $61.07 \pm 9.74$ & $>0.001$ \\
\hline Plasma PTH (pmol/L) & $5.39 \pm 2.07$ & $6.60 \pm 2.47$ & $5.00 \pm 1.92$ & $4.69 \pm 0.92$ & 0.030 \\
\hline Serum calcium (mmol/L) & $2.30 \pm 0.07$ & $2.28 \pm 0.05$ & $2.29 \pm 0.08$ & $2.31 \pm 0.05$ & 0.634 \\
\hline \multicolumn{6}{|l|}{$4 \%$ site } \\
\hline $\mathrm{BMC}(\mathrm{g} / \mathrm{cm})$ & $1.07 \pm 0.14$ & $1.06 \pm 0.12$ & $1.07 \pm 0.15$ & $1.10 \pm 0.13$ & 0.782 \\
\hline \multicolumn{6}{|l|}{$\operatorname{vBMD}\left(\mathrm{mg} / \mathrm{cm}^{3}\right):$} \\
\hline Total & $352.23 \pm 51.81$ & $355.81 \pm 40.47$ & $356.86 \pm 57.76$ & $337.95 \pm 50.35$ & 0.630 \\
\hline Trabecular & $199.29 \pm 57.78$ & $189.56 \pm 25.61$ & $208.46 \pm 63.39$ & $185.91 \pm 57.87$ & 0.462 \\
\hline \multicolumn{6}{|l|}{$66 \%$ site } \\
\hline $\mathrm{BMC}(\mathrm{g} / \mathrm{cm})$ & $0.96 \pm 0.14$ & $0.97 \pm 0.13$ & $0.96 \pm 0.16$ & $0.92 \pm 0.05$ & 0.642 \\
\hline \multicolumn{6}{|l|}{$\operatorname{vBMD}\left(\mathrm{mg} / \mathrm{cm}^{3}\right):$} \\
\hline Total & $714.39 \pm 86.33$ & $658.54 \pm 104.23^{a, b}$ & $732.91 \pm 73.85^{a}$ & $743.62 \pm 53.80^{b}$ & 0.014 \\
\hline Cortical & $1127.23 \pm 36.44$ & $1107.74 \pm 44.43^{c}$ & $1136.66 \pm 31.41^{c}$ & $1128.24 \pm 28.01$ & 0.049 \\
\hline
\end{tabular}

${ }^{1}$ Values: mean \pm SD. ${ }^{2}$ Statistical analysis: one-way ANOVA with post-hoc Tukey's test. Values in the same row with the same superscript letters are significantly different $\left({ }^{\mathrm{a}} p=0.019,{ }^{\mathrm{b}} p=0.044,{ }^{\mathrm{c}} p=0.039\right)$. 
There were no significant differences in any bone parameter measurements by vitamin $\mathrm{D}$ status for Brazilian women living in Brazil (Table 7).

Table 7. Lumbar spine and femur bone densitometry assessed by DXA of Brazilian women living in Brazil by vitamin D status $(n=79)^{1}$.

\begin{tabular}{|c|c|c|c|c|c|}
\hline \multirow{2}{*}{ Bone Parameter } & \multirow{2}{*}{ All } & \multicolumn{3}{|c|}{$25(\mathrm{OH}) \mathrm{D}$ in $\mathrm{nmol} / \mathrm{L}$} & \multirow{2}{*}{$p$ Value $^{2}$} \\
\hline & & $25-49.99$ & $50-74.99$ & $>75$ & \\
\hline Weight (kg) & $63.21 \pm 13.07$ & $57.49 \pm 10.73$ & $62.51 \pm 12.24$ & $65.03 \pm 13.97$ & 0.278 \\
\hline Height (m) & $1.62 \pm 0.59$ & $1.60 \pm 0.06$ & $1.62 \pm 0.06$ & $1.62 \pm 0.05$ & 0.625 \\
\hline BMI $\left(\mathrm{kg} / \mathrm{m}^{2}\right)$ & $24.01 \pm 4.88$ & $22.4 \pm 3.09$ & $23.65 \pm 4.71$ & $24.64 \pm 5.29$ & 0.409 \\
\hline Serum 25(OH)D (nmol/L) & $75.00 \pm 22.13$ & $42.77 \pm 4.12$ & $61.86 \pm 7.05$ & $92.11 \pm 16.31$ & $>0.001$ \\
\hline Plasma PTH (pmol/L) & $4.49 \pm 1.47$ & $4.73 \pm 1.23$ & $4.50 \pm 1.53$ & $4.42 \pm 1.51$ & 0.86 \\
\hline Serum calcium (mmol/L) & $2.28 \pm 0.06$ & $2.28 \pm 0.06$ & $2.28 \pm 0.07$ & $2.28 \pm 0.06$ & 0.993 \\
\hline \multicolumn{6}{|l|}{ Lumbar Spine } \\
\hline Number (n) & 79 & 9 & 30 & 40 & 0.716 \\
\hline $\mathrm{BMD}\left(\mathrm{mg} / \mathrm{cm}^{2}\right)$ & $1.13 \pm 0.11$ & $1.11 \pm 0.11$ & $1.13 \pm 0.12$ & $1.14 \pm 0.10$ & \\
\hline \multicolumn{6}{|l|}{ Femur } \\
\hline Number (n) & 64 & 8 & 25 & 31 & 0.728 \\
\hline $\mathrm{BMD}\left(\mathrm{mg} / \mathrm{cm}^{2}\right)$ & $0.98 \pm 0.10$ & $0.94 \pm 0.10$ & $0.97 \pm 0.10$ & $1.00 \pm 0.11$ & \\
\hline \multicolumn{6}{|l|}{ Total } \\
\hline Number (n) & 79 & 9 & 30 & 40 & 0.335 \\
\hline $\mathrm{BMC}(\mathrm{g})$ & $2395.43 \pm 381.24$ & $2305.66 \pm 372.97$ & $2391.46 \pm 448.47$ & $2418.60 \pm 331.93$ & \\
\hline
\end{tabular}

${ }^{1}$ Values: mean \pm SD. ${ }^{2}$ Statistical analysis: one-way ANOVA with post-hoc Tukey's test.

\subsection{Correlations between Bone Parameters and PTH Concentrations}

Overall (women living in Brazil combined with those living in England, $n=130$ ), plasma PTH concentrations were negatively correlated with $25(\mathrm{OH}) \mathrm{D}$ concentrations $(\mathrm{r}=-0.285, p=0.001)$. Within each group, plasma PTH concentrations were also negatively correlated with $25(\mathrm{OH}) \mathrm{D}$ concentrations in women living in the UK $(\mathrm{r}=-0.286, p=0.042)$, but not in those living in Brazil $(\mathrm{r}=-0.113$, $p=0.323)$. In total $(n=130), 10.4 \%$ of participants presented with secondary hyperparathyroidism (PTH concentrations $>6.9 \mathrm{pmol} / \mathrm{L}$ ). The prevalence of secondary hyperparathyroidism according to vitamin D status was $28.6 \%$ among participants with concentrations $<25 \mathrm{nmol} / \mathrm{L}(n=14)$ and $12.2 \%$ within participants with concentrations between 25 and $49.9 \mathrm{nmol} / \mathrm{L}(n=41)$. Only 3 participants with concentrations between 50 and $74.9 \mathrm{nmol} / \mathrm{L}$ and 2 participants with concentrations $>75 \mathrm{nmol} / \mathrm{L}$ presented with secondary hyperparathyroidism $(p=0.086$ for comparison of prevalence across status groups) (Figure 1). When analyzed separately for the two groups of women, the difference in the prevalence of secondary hyperparathyroidism was more evident between the two lower cut-off points for women living in England (Figure 2) and between the two highest cut-off points for women living in Brazil (Figure 3).

Correlations between radial bone parameter measurements, determined by pQCT, and PTH concentrations for women living in England are shown in Table 8. There was a significant positive association between PTH concentrations and BMC at both the $4 \%$ and $66 \%$ sites $(p=0.0012$ and $p=0.001$, respectively). Total vBMD at the $66 \%$ site was significantly negatively correlated with PTH concentrations $(p=0.026)$. However, after controlling for age and BMI, significance remained only for BMC at the diaphyseal site $(p=0.039)$, but not for BMC at the distal site or total vBMD at the diaphyseal site $(p=0.064$ and $p=0.078$, respectively). 


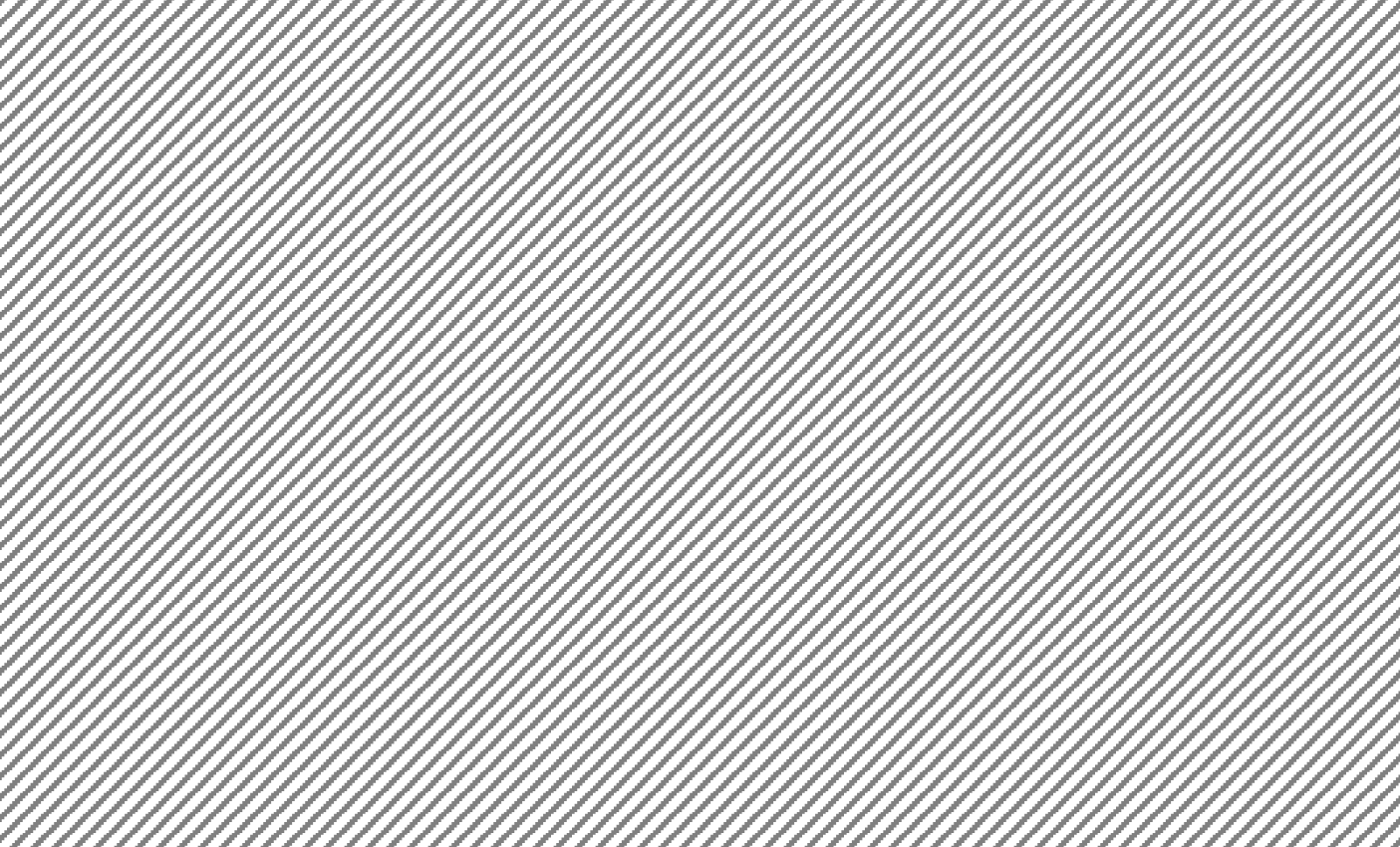

Figure 1. Prevalence of secondary hyperparathyroidism (Parathyroid Hormone $>6.9 \mathrm{pmol} / \mathrm{L}$ ) according to vitamin D status in Brazilian women recruited to a vitamin D supplementation study $(n=130)$.

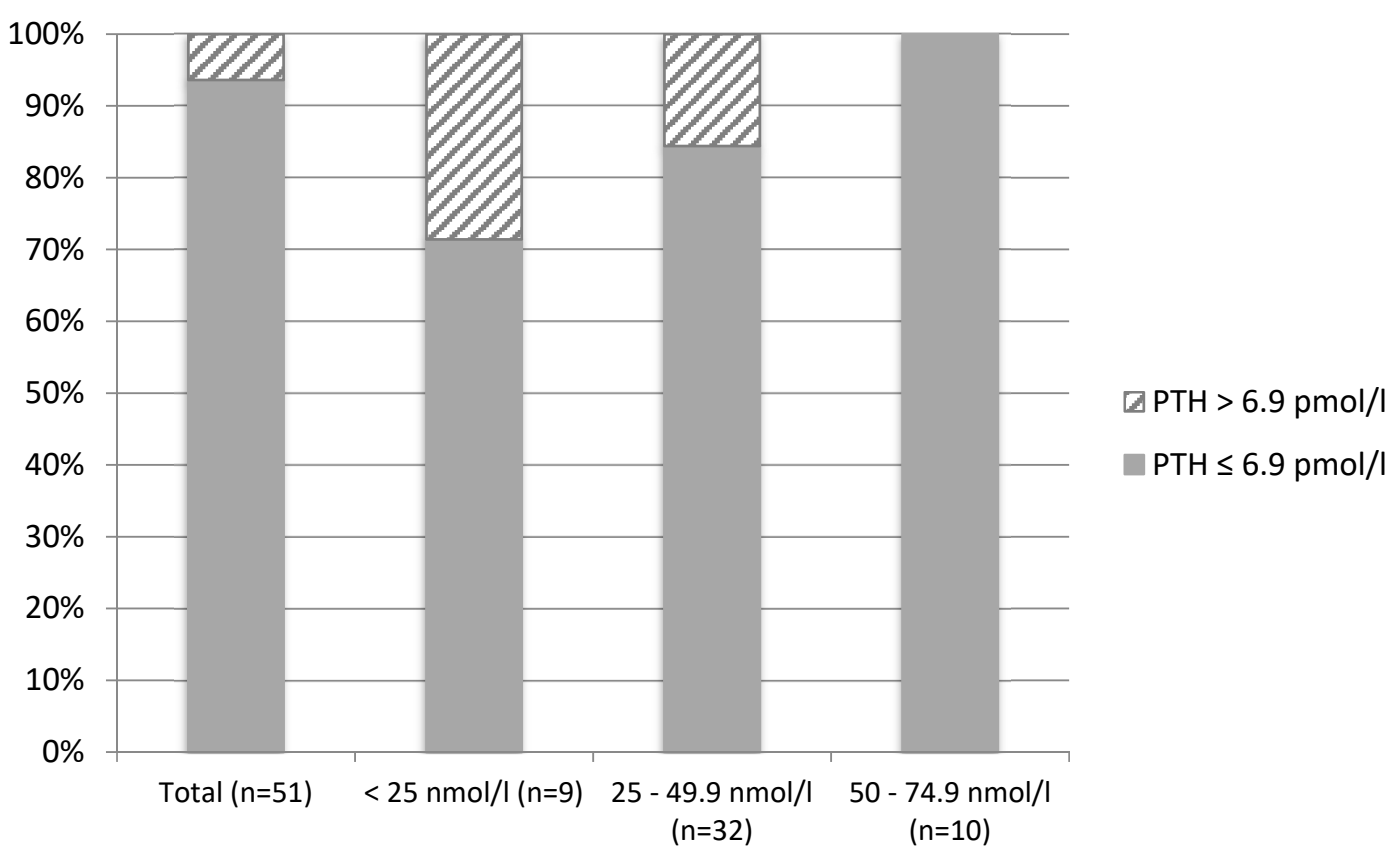

Figure 2. Prevalence of secondary hyperparathyroidism $(\mathrm{PTH}>6.9 \mathrm{pmol} / \mathrm{L})$ according to vitamin D status in Brazilian women living in England $(n=51)$.

There were no significant correlations between lumbar spine (L1-L4) and femur bone parameter measurements, determined by DXA, and PTH concentrations for women living in Brazil (Table 9). 


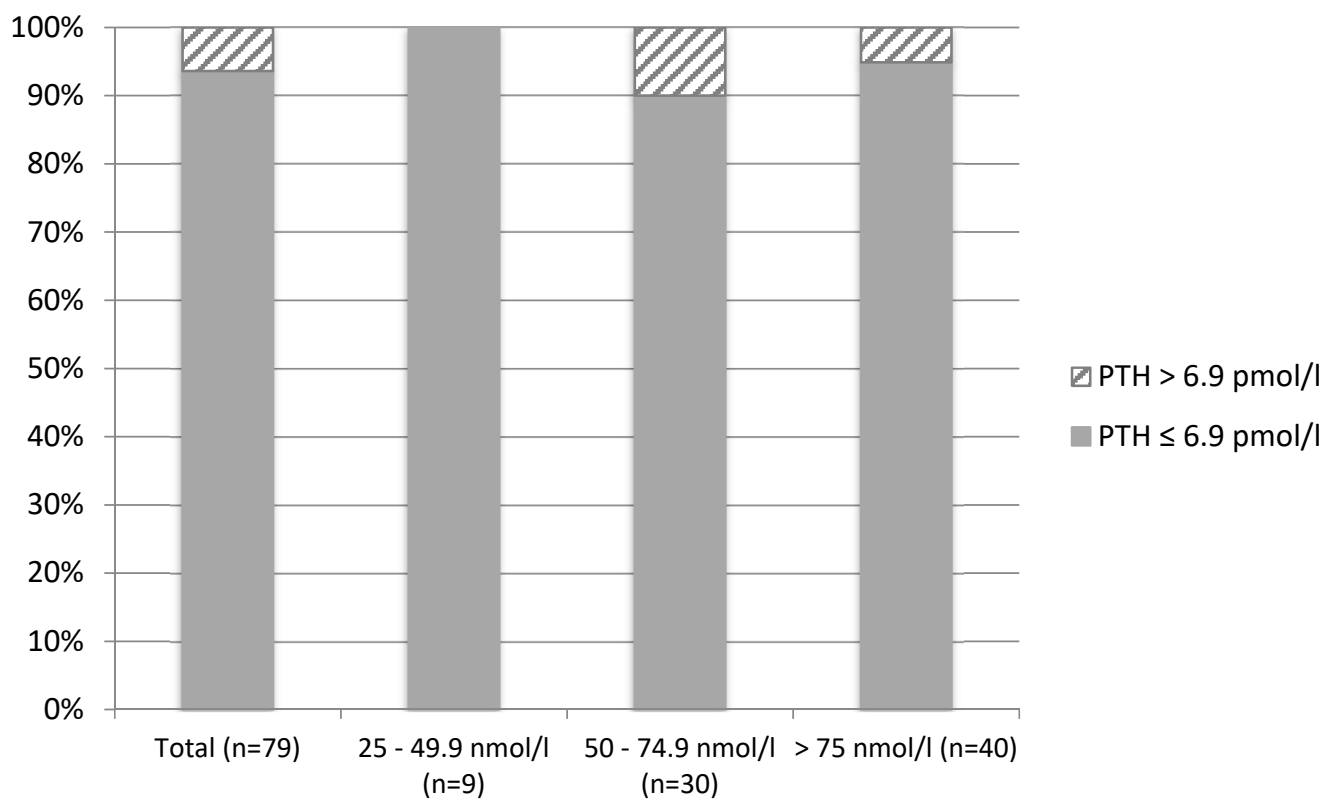

Figure 3. Prevalence of secondary hyperparathyroidism (PTH $>6.9 \mathrm{pmol} / \mathrm{L})$ according to vitamin D status in Brazilian women living in Brazil $(n=79)$.

Table 8. Associations between PTH concentrations and radial bone densitometry assessed by pQCT of Brazilian women living in England $(n=51)^{1}$.

\begin{tabular}{ccc}
\hline \multirow{2}{*}{ Bone Parameter } & \multicolumn{2}{c}{ PTH } \\
\cline { 2 - 3 } & r Value & $p$ Value \\
\hline $4 \%$ site & \\
\hline BMC $(\mathrm{g} / \mathrm{cm})$ & 0.348 & 0.012 \\
Total vBMD $\left(\mathrm{mg} / \mathrm{cm}^{3}\right)$ & 0.108 & 0.45 \\
Trabecular vBMD $\left(\mathrm{mg} / \mathrm{cm}^{3}\right)$ & 0.085 & 0.553 \\
\hline 66\% site & & \\
\hline BMC $(\mathrm{g} / \mathrm{cm})$ & 0.435 & 0.001 \\
Total vBMD $\left(\mathrm{mg} / \mathrm{cm}^{3}\right)$ & -0.312 & 0.026 \\
Cortical vBMD $\left(\mathrm{mg} / \mathrm{cm}^{3}\right)$ & -0.184 & 0.197 \\
\hline
\end{tabular}

${ }^{1}$ Pearson's correlation.

Table 9. Correlations between PTH concentrations and lumbar spine and femur bone densitometry assessed by DXA of Brazilian women living in Brazil $(n=78)^{1}$.

\begin{tabular}{ccc}
\hline \multirow{2}{*}{ Bone Parameter } & \multicolumn{2}{c}{ PTH } \\
\cline { 2 - 3 } & r Value & $p$ Value \\
\hline Lumbar Spine BMD $\left(\mathrm{mg} / \mathrm{cm}^{2}\right)(n=78)$ & 0.004 & 0.976 \\
Femur BMD $\left(\mathrm{mg} / \mathrm{cm}^{2}\right)(n=63)$ & 0.215 & 0.900 \\
Total BMC $(\mathrm{g})(n=78)$ & 0.114 & 0.319 \\
\hline
\end{tabular}

${ }^{1}$ Pearson's correlation.

\section{Discussion}

Vitamin D is essential for musculoskeletal health, and there is a consensus that serum concentrations should be at least $25 \mathrm{nmol} / \mathrm{L}$ to prevent detrimental effects on bone [1-3]. The present cross-sectional analysis of healthy adult women showed that amongst Brazilian women living in England, all participants presented a normal radial z-score. Amongst women living in Brazil, only 
two participants (2.5\%) presented with low bone mineral for age for the lumbar spine. Furthermore, bone parameters were significantly associated with weight and BMI in participants in both the England and Brazil cohorts, and with age in women living in Brazil only. This study also found that for women living in England, those with vitamin D deficiency $(<25 \mathrm{nmol} / \mathrm{L})$ had significantly lower total vBMD at the $66 \%$ site than those with greater concentrations, independent of age and BMI. This observation at the cortical site (66\%) only is likely due to the fact that most bone loss is the result of intracortical and endocortical remodeling, which produces cortical porosity and cortical thinning. Therefore, any alteration of BMD would be first evidenced at the cortical (66\%) in comparison to the trabecular $(4 \%)$ site. There were no associations between $25(\mathrm{OH}) \mathrm{D}$ status and any of the measures from the DXA scan in participants from the Brazil cohort, although the range of vitamin D status was smaller and the generally better vitamin D status of this sub-group may have limited the observation of effects on the bone. Nevertheless, the finding of bone parameters being significantly associated with the 25(OH)D/PTH system in women living in England, but not in those living in Brazil, together with the finding that plasma PTH concentrations were negatively correlated with $25(\mathrm{OH}) \mathrm{D}$ concentrations in women living in the UK, but not in those living in Brazil, are relevant for speculating on the possible role of different lifestyles and climates in mediating the relationship between $25(\mathrm{OH}) \mathrm{D}, \mathrm{PTH}$, and bone.

The associations between bone parameters and weight and BMI suggest that the observed poorer bone health in this sample is likely to be due to lower weights. These findings are in agreement with several studies that have demonstrated positive associations between BMI and bone parameters, likely explained by a greater load on weight-bearing bones [23-25]. In a cross-sectional study investigating a total of 412 Brazilian postmenopausal women, aged 40 to 75 years with BMD assessed by DXA at the lumbar spine, a higher BMI was associated with reduced osteoporosis risk [26]. A study with 393 post-menopausal Brazilian women reported a lower prevalence of osteopenia and osteoporosis amongst obese women compared to those with eutrophic BMI (DXA-derived BMD assessment) [27]. Another study in São Paulo, with 413 Brazilian women (52.5\% $<59$ years and $47.5 \%>60$ years) showed the BMI to be a positive predictor for DXA-derived BMD at the femoral neck [28]. For women living in England, there was an inverse statistically significant correlation between vBMD at the $66 \%$ site (total and cortical) and weight. Some studies have reported similar findings of the inverse correlation in the cortical site of the radius observed in this study $[29,30]$. Some hypotheses to explain this include variances in bone geometry or bone damage, increased bone turnover, and a momentary reduction in vBMD due to increased mechanical loading. Further investigation is now required, especially in adult women under 50 years of age, to better understand these relationships [29,31,32].

To date, there are still few longitudinal studies that have investigated the association of long-term lower calcium intake with bone health outcomes later in life, particularly from a younger starting age, i.e., <30-35 years. A longitudinal study of 5022 women (born between 1914 and 1948 and followed up for 19 years) with modest dietary calcium intake reported that only the lowest quintile of calcium intake $(<751 \mathrm{mg})$ was associated with increased risk of fracture or osteoporosis [33]. It has been suggested that the association between calcium and BMD might not be consistently linear, and a sufficient vitamin D status is likely to compensate for the negative effects of low calcium intake on bone [34-36].

In the United Kingdom, the latest national survey reported mean dietary calcium intakes of 897 and $746 \mathrm{mg} /$ day for men and women aged 19 to 64 years, respectively (NDNS years 7-8, 2015-2016). In Brazil, the latest national survey available to date reported that mean dietary calcium intakes were 546.4 and $476.4 \mathrm{mg} /$ day for men and women aged 20 to 59 years, respectively (POF, 2008-2009) [37]. In this study, $72.8 \%$ of participants had dietary calcium intakes below the RNI of $700 \mathrm{mg} / \mathrm{day}$, while only $5.2 \%$ met the $1000 \mathrm{mg} /$ day RDA reference. All participants had dietary vitamin D intakes below the $15 \mu \mathrm{g} /$ day RDA recommended by the IOM [21] and 99.2\% had intakes below the RNI of $10 \mu \mathrm{g} /$ day proposed by SACN [20]. Despite this, there were no significant correlations between bone parameter measurements and habitual dietary vitamin D and calcium intakes, either for England or Brazil dwelling participants, perhaps again reflecting the narrow range of intakes and therefore lack of discriminatory power in this sample. 
Elevated concentrations of serum PTH are associated with several adverse outcomes, particularly musculoskeletal outcomes [38-40]. Secondary hyperparathyroidism may lead to bone loss due to increased bone turnover rates $[38,41]$. Several studies have shown $25(\mathrm{OH}) \mathrm{D}$ to be inversely correlated with PTH $[10,38,40,42]$. The present study confirms this with $25(\mathrm{OH}) \mathrm{D}$ concentrations being inversely correlated with PTH concentrations in healthy adult women. Additionally, $10.4 \%$ of participants had secondary hyperparathyroidism, with a higher prevalence amongst those with deficient and insufficient vitamin D status. The difference in the prevalence of secondary hyperparathyroidism was more evident between the two lower cut-off points for women living in England and between the two highest cut-off points for women living in Brazil, which might be explained by the significant difference in the mean and range of 25(OHD concentrations between the two groups. Due to the strong inverse correlation between $25(\mathrm{OH}) \mathrm{D}$ and PTH concentrations, individuals with deficient and insufficient vitamin D status would very likely benefit from vitamin D supplementation with a view to suppressing PTH secretion from the parathyroid gland.

Moreover, several studies have also shown an inverse correlation between serum PTH levels and BMD [40,41]. In this study, a negative correlation between PTH concentrations and total BMD at the $66 \%$ site was seen, although this was not significant after controlling for age and BMI. There were no associations with PTH levels and any of the measures from the DXA scan in participants from the Brazil cohort, which may be due to long-term detrimental consequences of higher PTH levels not yet being evident in the relatively young women in this study.

The associations between 25(OH)D, PTH, and bone mineral density (BMD) are still much debated. Evidence is more robust in specific subgroups, such as in those with low vitamin D levels [39], in osteoporotic subjects $[9,11]$, post-menopausal women $[9,11,43,44]$, or in the elderly $[14,38,45]$. The findings presented here are in accordance with previous reports of studies that included healthy younger adults as well as those that encompass the whole spectrum of vitamin D status (i.e., deficient, sufficient, and adequate), demonstrating the absence of any association between $25(\mathrm{OH}) \mathrm{D}$ or PTH and BMD $[13,46,47]$. The reasons for no effects on bone parameters might be due to the lack of power within the deficient subgroup and the relatively young participants, who might not be currently affected by potential long-term detrimental outcomes from low 25(OH)D and high PTH concentrations. Further studies are now required to better understand the effects of inadequate concentrations of $25(\mathrm{OH}) \mathrm{D}$ or PTH on bone health specifically in younger otherwise healthy women and future health consequences.

The strengths of this study include the fact that both measurements used for bone density assessment, pQCT and DXA scan, are considered gold standard methods. The analysis controlled for possible confounders, such as age, weight, and BMI. A limitation of the study is that the DXA scan software reports using a combination of databases to calculate the Z-score, while for the PQCT data a specific published reference data was used. Ideally, the same method would have been used for both groups, and a DXA scan would be the preferred option, as it has been shown to be an accurate diagnostic clinical tool and would have provided a central measurement for all participants [48]. It might be that there was insufficient statistical power in this sample to detect significant differences in bone parameters and serum $25(\mathrm{OH}) \mathrm{D}$ and PTH concentrations. This analysis would benefit from further measures of biochemical markers of bone turnover to further investigate the relationship of $25(\mathrm{OH}) \mathrm{D}, \mathrm{PTH}$, and bone health in these adult women.

In conclusion, weight and BMI were significantly correlated with bone parameters in both groups and age was significantly correlated with BMD at the femoral neck for women living in Brazil only. Although 25(OH)D concentrations were not correlated to bone parameters at any sites, in either country, PTH concentrations showed a significant correlation with total vBMD at the $66 \%$ site for women living in England. This analysis also showed that secondary hyperparathyroidism was more common amongst those with a deficient and insufficient vitamin D status. There were no significant correlations between bone parameters and the usual dietary intake of vitamin $\mathrm{D}$ and calcium, in either of the groups. 
Supplementary Materials: The following are available online at http:/www.mdpi.com/2072-6643/11/6/1267/s1, Table S1: Characteristics of Brazilian women living in England by tertile of $4 \%$ Total vBMD $(n=51)$; Table S2: Characteristics of Brazilian women living in England by tertile of $4 \%$ Trabecular vBMD $(n=51)$; Table S3: Characteristics of Brazilian women living in England by tertile of $66 \%$ Cortical vBMD $(n=51)$; Table S4: Characteristics of Brazilian women living in England by tertile of $66 \%$ Total vBMD $(n=51)$; Table S5: Characteristics of Brazilian women living in Brazil by tertile of lumbar spine BMD $(n=79)$; Table S6: Characteristics of Brazilian women living in Brazil by tertile of femur BMD $(n=64)$.

Author Contributions: Conceptualization, M.M.M., K.H.H., S.A.L.-N. and P.B.B.; methodology M.M.M., K.H.H., S.A.L.-N. and P.B.B.; formal analysis, M.M.M.; investigation, M.M.M.; resources, M.M.M., K.H.H., S.A.L.-N. and P.B.B.; data curation, M.M.M.; writing—original draft preparation, M.M.M.; writing-review and editing, M.M.M., K.H.H., S.A.L.-N. and P.B.B; visualization, M.M.M.; supervision, K.H., S.A.L.-N. and P.B.B.; project administration, M.M.M., K.H.H., S.A.L.-N. and P.B.B.; funding acquisition M.M.M., K.H.H., S.A.L.-N. and P.B.B.

Funding: This research was funded by the Brazilian National Council for Scientific and Technological Development, grant number 235046/2014.

Acknowledgments: The authors would like to acknowledge the collaboration of the Faculty of Nutrition, Federal University of Goiás, and its collaborators.

Conflicts of Interest: S.A.L.-N. is Research Director of D3Tex Ltd., which holds the UK and Gulf Corporation Council (GCC) Patent for the use of UVB transparent material for vitamin D deficiency prevention. The funders had no role in the design of the study; in the collection, analyses, or interpretation of data; in the writing of the manuscript, or in the decision to publish the results.

\section{References}

1. Heaney, R. Calcium in the treatment of osteoporosis. In Osteoporosis: Fourth Edition; Marcus, R., Dempster, D., Cauley, J., Feldman, D., Eds.; Academic Press: Cambridge, MA, USA, 2013; pp. 1691-1700.

2. Peacock, M. Calcium metabolism in health and disease. Clin. J. Am. Soc. Nephrol. 2010, 5, S23-S30. [CrossRef] [PubMed]

3. DeLuca, H.F. Overview of general physiologic features and functions of vitamin D. Am. J. Clin. Nutr. 2004, 80, 1689S-1696S. [CrossRef] [PubMed]

4. Reid, I.R.; Bolland, M.J.; Grey, A. Effects of vitamin D supplements on bone mineral density: A systematic review and meta-analysis. Lancet 2014, 383, 146-155. [CrossRef]

5. Tang, B.M.; Eslick, G.D.; Nowson, C.; Smith, C.; Bensoussan, A. Use of calcium or calcium in combination with vitamin D supplementation to prevent fractures and bone loss in people aged 50 years and older: A meta-analysis. Lancet 2007, 370, 657-666. [CrossRef]

6. Silk, L.N.; Greene, D.A.; Baker, M.K. The effect of calcium or calcium and vitamin D supplementation on bone mineral density in healthy males: A systematic review and meta-analysis. Int. J. Sport Nutr. Exerc. Metab. 2015, 25, 510-524. [CrossRef] [PubMed]

7. Jackson, R.D.; LaCroix, A.Z.; Gass, M.; Wallace, R.B.; Robbins, J.; Lewis, C.E.; Bassford, T.; Beresford, S.A.; Black, H.R.; Blanchette, P.; et al. Calcium plus vitamin D supplementation and the risk of fractures. N. Engl. J. Med. 2006, 354, 669-683. [CrossRef] [PubMed]

8. Chapuy, M.C.; Pamphile, R.; Paris, E.; Kempf, C.; Schlichting, M.; Arnaud, S.; Garnero, P.; Meunier, P.J. Combined calcium and vitamin D3 supplementation in elderly women: Confirmation of reversal of secondary hyperparathyroidism and hip fracture risk: The decalyos ii study. Osteoporos. Int. 2002, 13, 257-264. [CrossRef]

9. Dawson-Hughes, B.; Harris, S.S.; Krall, E.A.; Dallal, G.E. Effect of calcium and vitamin D supplementation on bone density in men and women 65 years of age or older. New Engl. J. Med. 1997, 337, 670-676. [CrossRef]

10. Vieth, R.; Ladak, Y.; Walfish, P.G. Age-related changes in the 25-hydroxyvitamin D versus parathyroid hormone relationship suggest a different reason why older adults require more vitamin D. J. Clin. Endocr. Metab. 2003, 88, 185-191. [CrossRef]

11. Lips, P.; Duong, T.; Oleksik, A.; Black, D.; Cummings, S.; Cox, D.; Nickelsen, T.; Ste-Marie, L.G.; Evalu, M.O.R. A global study of vitamin D status and parathyroid function in postmenopausal women with osteoporosis: Baseline data from the multiple outcomes of raloxifene evaluation clinical trial. J. Clin. Endocr. Metab. 2001, 86, 1212-1221. [CrossRef]

12. Saraiva, G.L.; Cendoroglo, M.S.; Ramos, L.R.; Araujo, L.M.; Vieira, J.G.; Maeda, S.S.; Borba, V.Z.; Kunii, I.; Hayashi, L.F.; Lazaretti-Castro, M. Prevalence of vitamin D deficiency, insufficiency and secondary 
hyperparathyroidism in the elderly inpatients and living in the community of the city of Sao Paulo, Brazil. Arq. Bras. Endocrinol. Metabol. 2007, 51, 437-442. [CrossRef] [PubMed]

13. Moreno-Reyes, R.; Carpentier, Y.A.; Boelaert, M.; El Moumni, K.; Dufourny, G.; Bazelmans, C.; Leveque, A.; Gervy, C.; Goldman, S. Vitamin D deficiency and hyperparathyroidism in relation to ethnicity: A cross-sectional survey in healthy adults. Eur. J. Nutr. 2009, 48, 31-37. [CrossRef] [PubMed]

14. Melin, A.L.; Wilske, J.; Ringertz, H.; Saaf, M. Vitamin D status, parathyroid function and femoral bone density in an elderly swedish population living at home. Aging Clin. Exp. Res. 1999, 11, 200-207. [CrossRef]

15. Russo, L.A.; Gregorio, L.H.; Lacativa, P.G.; Marinheiro, L.P. Concentration of 25-hydroxyvitamin D in postmenopausal women with low bone mineral density. Arq. Bras. Endocrinol. Metabol. 2009, 53, 1079-1087. [CrossRef] [PubMed]

16. Chen, T.C.; Chimeh, F.; Lu, Z.R.; Mathieu, J.; Person, K.S.; Zhang, A.Q.; Kohn, N.; Martinello, S.; Berkowitz, R.; Holick, M.F. Factors that influence the cutaneous synthesis and dietary sources of vitamin D. Arch. Biochem. Biophys. 2007, 460, 213-217. [CrossRef]

17. Marfell-Jones, M.J.; Stewart, A.D.; De Ridder, J.H. International Standards for Anthropometric Assessment; International Society for the Advancement of Kinanthropometry: Lower Hutt, New Zealand, 2012.

18. Burt, L.A.; Macdonald, H.M.; Hanley, D.A.; Boyd, S.K. Bone microarchitecture and strength of the radius and tibia in a reference population of young adults: An hr-pqct study. Arch. Osteoporos. 2014, 9, 183. [CrossRef]

19. Looker, A.C.; Wahner, H.W.; Dunn, W.L.; Calvo, M.S.; Harris, T.B.; Heyse, S.P.; Johnston, C.C., Jr.; Lindsay, R. Updated data on proximal femur bone mineral levels of us adults. Osteoporos. Int. 1998, 8, 468-489. [CrossRef]

20. Scientific Advisory Committee on Nutrition (SCAN). Vitamin D and Health; Scientific Advisory Committee on Nutrition: London, UK, 2016.

21. Ross, A.C.; Manson, J.E.; Abrams, S.A.; Aloia, J.F.; Brannon, P.M.; Clinton, S.K.; Durazo-Arvizu, R.A.; Gallagher, J.C.; Gallo, R.L.; Jones, G.; et al. The 2011 report on dietary reference intakes for calcium and vitamin D from the institute of medicine: What clinicians need to know. J. Clin. Endocrinol. Metab. 2011, 96, 53-58. [CrossRef]

22. Public Health England. Government recommendations for energy and nutrients for males and females aged 1-18 years and 19+ years. In Government Dietary Recommendations; Public Health England: London, UK, 2016.

23. Felson, D.T.; Zhang, Y.; Hannan, M.T.; Anderson, J.J. Effects of weight and body mass index on bone mineral density in men and women: The framingham study. J. Bone Miner. Res. 1993, 8, 567-573. [CrossRef]

24. Johansson, H.; Kanis, J.A.; Oden, A.; McCloskey, E.; Chapurlat, R.D.; Christiansen, C.; Cummings, S.R.; Diez-Perez, A.; Eisman, J.A.; Fujiwara, S.; et al. A meta-analysis of the association of fracture risk and body mass index in women. J. Bone Miner. Res. 2014, 29, 223-233. [CrossRef]

25. De Laet, C.; Kanis, J.A.; Oden, A.; Johanson, H.; Johnell, O.; Delmas, P.; Eisman, J.A.; Kroger, H.; Fujiwara, S.; Garnero, P.; et al. Body mass index as a predictor of fracture risk: A meta-analysis. Osteoporosis. Int. 2005, 16, 1330-1338. [CrossRef] [PubMed]

26. Nahas, E.A.P.; Kawakami, M.S.; Nahas-Neto, J.; Buttros, D.D.; Cangussu, L.; Rodrigues, A.B. Assessment of risk factors for low bone mineral density in brazilian postmenopausal women. Climacteric 2011, 14, 220-227. [CrossRef]

27. Mazocco, L.; Chagas, P. Association between body mass index and osteoporosis in women from northwestern Rio Grande do Sul. Rev. Bras. Reumatol. 2017, 57, 299-305. [CrossRef]

28. Frazao, P.; Naveira, M. Factors associated with low bone mineral density among white women. Rev. Saude Publica 2007, 41, 740-748. [PubMed]

29. Barbour, K.E.; Zmuda, J.M.; Strotmeyer, E.S.; Horwitz, M.J.; Boudreau, R.; Evans, R.W.; Ensrud, K.E.; Petit, M.A.; Gordon, C.L.; Cauley, J.A. Correlates of trabecular and cortical volumetric bone mineral density of the radius and tibia in older men: The Osteoporotic Fractures in Men Study. J. Bone Miner. Res. 2010, 25, 1017-1028. [CrossRef]

30. Sheu, Y.; Cauley, J.A.; Bunker, C.H.; Wheeler, V.W.; Patrick, A.L.; Gordon, C.L.; Kammerer, C.M.; Zmuda, J.M. Correlates of trabecular and cortical volumetric BMD in men of African ancestry. J. Bone Miner. Res. 2009, 24, 960-968. [CrossRef]

31. Burr, D.B. Remodeling and the repair of fatigue damage. Calcif. Tissue Int. 1993, 53, S75-S80. [CrossRef]

32. Lorentzon, M.; Landin, K.; Mellström, D.; Ohlsson, C. Leptin is a negative independent predictor of areal BMD and cortical bone size in young adult Swedish men. J. Bone Miner. Res. 2006, 21, 1871-1878. [CrossRef] 
33. Warensjo, E.; Byberg, L.; Melhus, H.; Gedeborg, R.; Mallmin, H.; Wolk, A.; Michaelsson, K. Dietary calcium intake and risk of fracture and osteoporosis: Prospective longitudinal cohort study. BMJ 2011, 342, d1473. [CrossRef]

34. Kim, K.M.; Choi, S.H.; Lim, S.; Moon, J.H.; Kim, J.H.; Kim, S.W.; Jang, H.C.; Shin, C.S. Interactions between dietary calcium intake and bone mineral density or bone geometry in a low calcium intake population (KNHANES IV 2008-2010). J. Clin. Endocr. Metab. 2014, 99, 2409-2417. [CrossRef]

35. Bischoff-Ferrari, H.A.; Kiel, D.P.; Dawson-Hughes, B.; Orav, J.E.; Li, R.; Spiegelman, D.; Dietrich, T.; Willett, W.C. Dietary calcium and serum 25-hydroxyvitamin D status in relation to BMD among US adults. J. Bone Miner. Res. 2009, 24, 935-942. [CrossRef] [PubMed]

36. Mezquita-Raya, P.; Munoz-Torres, M.; Luna, J.D.; Luna, V.; Lopez-Rodriguez, F.; Torres-Vela, E.; Escobar-Jimenez, F. Relation between vitamin D insufficiency, bone density, and bone metabolism in healthy postmenopausal women. J. Bone Miner. Res. 2001, 16, 1408-1415. [CrossRef] [PubMed]

37. POF. Pesquisa de orçamentos familiares 2008-2009. In Análise do Consumo Alimentar Pessoal no Brasil; Instituto Brasileiro de Geografia e Estatística - IBGE: Rio de Janeiro, Brazil, 2011.

38. Lips, P. Vitamin D deficiency and secondary hyperparathyroidism in the elderly: Consequences for bone loss and fractures and therapeutic implications. Endocr. Rev. 2001, 22, 477-501. [CrossRef] [PubMed]

39. Bouillon, R.; Van Schoor, N.M.; Gielen, E.; Boonen, S.; Mathieu, C.; Vanderschueren, D.; Lips, P. Optimal vitamin D status: A critical analysis on the basis of evidence-based medicine. J. Clin. Endocr. Metab. 2013, 98, E1283-E1304. [CrossRef] [PubMed]

40. Bischof Kota, S.; Jammula, S.; Kota, S.; Meher, L.; Modi, K. Correlation of vitamin D, bone mineral density and parathyroid hormone levels in adults with low bone density. Indian J. Orthop. 2013, 47, 402-407. [CrossRef] [PubMed]

41. Sahota, O.; Mundey, M.K.; San, P.; Godber, I.M.; Lawson, N.; Hosking, D.J. The relationship between vitamin $\mathrm{D}$ and parathyroid hormone: Calcium homeostasis, bone turnover, and bone mineral density in postmenopausal women with established osteoporosis. Bone 2004, 35, 312-319. [CrossRef]

42. Iuliano-Burns, S.; Ayton, J.; Hillam, S.; Jones, G.; King, K.; Macleod, S.; Seeman, E. Skeletal and hormonal responses to vitamin D supplementation during sunlight deprivation in antarctic expeditioners. Osteoporosis. Int. 2012, 23, 2461-2467. [CrossRef]

43. Villareal, D.T.; Civitelli, R.; Chines, A.; Avioli, L.V. Subclinical vitamin-d deficiency in postmenopausal women with low vertebral bone mass. J. Clin. Endocr. Metab. 1991, 72, 628-634. [CrossRef]

44. Bischoff-Ferrari, H.A.; Dietrich, T.; Orav, E.J.; Dawson-Hughes, B. Positive association between 25-hydroxy, vitamin D levels and bone mineral density: A population-based study of younger and older adults. Am. J. Med. 2004, 116, 634-639. [CrossRef]

45. Smith, L.M.; Gallagher, J.C.; Kaufmann, M.; Jones, G. Effect of increasing doses of vitamin D on bone mineral density and serum n-terminal telopeptide in elderly women: A randomized controlled trial. J. Intern. Med. 2018, 284, 685-693. [CrossRef]

46. Gannage-Yared, M.H.; Chemali, R.; Yaacoub, N.; Halaby, G. Hypovitaminosis d in a sunny country: Relation to lifestyle and bone markers. J. Bone Miner. Res. 2000, 15, 1856-1862. [CrossRef] [PubMed]

47. Olmos, J.M.; Hernandez, J.L.; Garcia-Velasco, P.; Martinez, J.; Llorca, J.; Gonzalez-Macias, J. Serum 25-hydroxyvitamin d, parathyroid hormone, calcium intake, and bone mineral density in Spanish adults. Osteoporos. Int. 2016, 27, 105-113. [CrossRef] [PubMed]

48. Liu, X.S.; Cohen, A.; Shane, E.; Yin, P.T.; Stein, E.M.; Rogers, H.; Kokolus, S.L.; McMahon, D.J.; Lappe, J.M.; Recker, R.R.; et al. Bone Density, Geometry, Microstructure and Stiffness: Relationships Between Peripheral and Central Skeletal Sites Assessed by DXA, HR-pQCT, and cQCT in Premenopausal Women. J. Bone Miner. Res. 2010, 25, 2229-2238. [CrossRef] [PubMed]

(C) 2019 by the authors. Licensee MDPI, Basel, Switzerland. This article is an open access article distributed under the terms and conditions of the Creative Commons Attribution (CC BY) license (http://creativecommons.org/licenses/by/4.0/). 